\title{
Understanding the Properties of Silicon Solar Cells Aluminium Contact Layers and Its Effect on Mechanical Stability
}

\author{
V. A. Popovich ${ }^{1}$, M. P. F. H. L. van Maris $^{2}$, M. Janssen ${ }^{1}$, I. J. Bennett ${ }^{3}$, I. M. Richardson ${ }^{1}$ \\ ${ }^{1}$ Department of Materials Science \& Engineering, Delft University of Technology, Delft, The Netherlands; ${ }^{2}$ Department of Me- \\ chanical Engineering, Eindhoven University of Technology, Eindhoven, The Netherlands; ${ }^{3}$ Solar Energy, PV Module Technology, \\ Energy Research Centre of the Netherlands, Petten, The Netherlands. \\ Email: v.popovich@tudelft.nl
}

Received October $26^{\text {th }}, 2012$; revised November $25^{\text {th }}, 2012$; accepted December $23^{\text {rd }}, 2012$

\begin{abstract}
As the thickness of silicon solar wafer and solar cells becomes thinner, the cells are subjected to high stress due to the thermal coefficient mismatch induced by metallization process. Handling and bowing problems associated with thinner wafers become increasingly important, as these can lead to cells cracking and thus to high yield losses. The goal of this work to provide experimental understanding of $\mathrm{Al}$ rear side microstructure development and mechanical properties as well as correlate the obtained results with fracture behaviour of the cell. It is shown that the aluminium back contact has a complex microstructure, consisting of five main components: 1) the back surface field layer; 2) a eutectic layer; 3 ) spherical $(3-5 \mu \mathrm{m})$ hypereutectic Al-Si particles surrounded by a thin aluminium oxide layer $(200 \mathrm{~nm}) ; 4)$ a bismuth-silicate glass matrix; and 5) pores (14 vol\%). It was concluded that the eutectic layer thickness and waviness depends on Al particle size, amount of Al paste and textured surface roughness of silicon wafers. The Young's modulus of the Al-Si particles is estimated by nano-indentation and the overall Young's modulus is estimated on the basis of bowing measurements and found to be $\sim 43 \mathrm{GPa}$. It was found, that there is a relation between aluminium paste composition, eutectic layer thickness, mechanical strength and bowing of solar cells. Three main parameters were found to affect the mechanical strength of mc-silicon solar cells with an aluminium contact layer, namely the eutectic layer thickness and uniformity, the Al layer thickness (which results from the Al particle size and its distribution), and the amount of porosity and the bismuth glass fraction.
\end{abstract}

Keywords: Al Back Contact; Fracture Strength; Bowing; Young’s Modulus; Silicon Solar Cell

\section{Introduction}

For crystalline silicon solar cells to satisfy future energy requirements there is still a significant need for reductions in system costs and improvements in manufacturing to increase throughput and production yield. Thus, in the near future, PV has to compete with other energy sources both in respect to electricity generation and investment costs. One key for the cost reduction is to reduce the silicon content, thus using a thinner wafer. However, this thickness reduction leads to a high breakage of silicon solar cells. Therefore, nowadays, a large research focus in the area of silicon solar cells is related to the factors influencing mechanical stability of crystalline silicon solar cell. Unfortunately, silicon wafers contain defects, created by the various processing steps involved in solar cell production, which reduce the strength of the wafer significantly. Consequently, a higher breakage rate is unavoidable if thinner wafers are produced with identical fracture strength in combination with the same loading during processing. Handling and bowing problems associated with thinner wafers become increasingly important, as these can lead to cells cracking and high yield losses. The most critical processing step during the manufacture of screen-printed solar cells is the firing process, during which the screen printed aluminium and silver layers are simultaneously fired in order to create electrical contacts. Residual stresses are generated within the cell due to mismatch of thermal expansion coefficients and different mechanical behaviour of the materials used in the metallic contacts. The wafer bows and forms a convex or concave body upon cooling, which mechanically loads the cell and may cause fracture [1]. As the thickness of silicon wafers is reduced, cell bowing becomes a major problem during different processing steps. It is possible to decrease bowing by reducing the amount of alumin- 
ium paste or by changing the paste chemistry and firing conditions. However, there is a limit below which screenprinted aluminium paste will lead to a non-uniform back surface field layer, influencing the electrical properties of the cell [2-4]. Nowadays it is very important to find a compromise between electrical properties, strength and costs of the solar cell. To achieve this, it is necessary to have a better understanding of microstructure, stress development and mechanical properties of the cell.

In this paper the results are reported from an investigation of the microstructure and mechanical properties of the aluminium at the rear side of the solar cell, and of the effect of the paste composition on bowing and mechanical strength. Several aspects related to solar cell processing conditions and metallization properties are described in relation to mechanical strength. On the basis of this knowledge, it should be possible to better determine mechanical limits of the solar cell with the aim of reducing yield losses during cell and module manufacture.

\section{Materials and Methods}

\subsection{Microstructural Analysis}

Silicon wafers of $156 \times 156 \mathrm{~mm}^{2}$ and a thickness of 200 $\mu \mathrm{m}$ were sliced off a single multi-crystalline silicon block. In this study, only wafers from the middle of the block contributed to the results. A standard industrial cell process was used and the screen printing on the rear was performed in the conventional H-pattern manner with a 165 mesh screen. To examine the influence of the type of aluminium paste on bowing, three different commercially available aluminium pastes were used (designated A, B and C).

Measurements of the amount of cell bowing were made by an optical method, using a Quick Vision Mitutoyo system. Five cells from neighbouring wafers were prepared for each type of aluminium paste. Measurements were performed over the full length of the solar cell $(156 \mathrm{~mm})$.

A JEOL JSM 6500F scanning electron microscope (SEM) with energy-dispersive spectroscopy (EDS) was used for microstructural analysis of cleaved samples of a conventional solar cell. In order to characterize the Al-Si reaction layer, samples were polished and etched in a solution of $\mathrm{HF}-\mathrm{HNO}_{3}-\mathrm{CH}_{3} \mathrm{COOH}$ (1:3:6) for 20 seconds. Metallic polishing holders were used to prevent any influence of embedding resin.

The composition was determined by electron probe micro analyses (EPMA). EPMA measurements were performed with a JEOL JXA 8900R microprobe using an electron beam with an energy of $15 \mathrm{keV}$ and a beam current of $20 \mathrm{nA}$ employing wavelength dispersive spectrometry (WDS). The composition at each analysis loca- tion of the sample was determined using the X-ray intensities of the constituent elements after background correction relative to the corresponding intensities of reference materials. The intensity ratios obtained were processed with a matrix correction program CITZAF [5]. The points of analysis were located along a line with increments of $0.5 \mu \mathrm{m}$ and involved the elements $\mathrm{Al}, \mathrm{Si}$ and $\mathrm{O}$. The data were normalized to 100 weight percent except where the composition amounted to a total of less than 100 weight percent.

Phase identification of the as-dried and sintered $\mathrm{Al}$ pastes was conducted by X-ray diffraction using a D8discover diffractometer $\left(\mathrm{Cu} \mathrm{K}_{\alpha}\right.$ radiation) equipped with an Euler cradle. A multiphase structure refinement was carried out by means of a full profile Rietveld method including refinement of the lattice parameters, atomic positions, scale factor, zero shift, background and Braggpeak profile parameters. Starting models for the calculation procedure were taken from the inorganic crystal structure database (ICSD) [6].

The particle size distribution via laser diffraction has been measured with a Malvern Mastersizer 2000 in a configuration from 0.02 up to $2000 \mu \mathrm{m}$ with Lorentz-Mie as optical model. The Hydro SM 100 millilitre sample dispersion unit has been used for dispersion of the aluminium paste samples.

The simultaneous application of Thermo-gravimetry (TG) and Differential Scanning Calorimetry (DSC) to a single sample in a Simultaneous Thermal Analysis (STA) was performed in order to evaluate the interaction between the aluminium back contact paste and silicon wafer material. Three different types of aluminium pastes were chosen and tested under measurement conditions close to the conventional industrial firing conditions. In these STA experiments, the aluminium pastes were analysed separately, as well as in contact with the silicon wafer.

High-resolution computed tomography was performed with a Nanotom system equipped with a high-power nano-focused tube $(180 \mathrm{kV} / 15 \mathrm{~W})$ to characterise the microstructure of the $\mathrm{Al}$ layer, the concentration profile of glass phases in the as-fired $\mathrm{Al}$ paste, as well as the porosity. This technique provides a three-dimensional spatial image of an object, distinguishing different materials on the basis of their density. Computed tomography $3 \mathrm{D}$ images were generated by rotation of the sample over $360^{\circ}$ with a step size of $0.5^{\circ}$, while taking a series of $2 \mathrm{D}$ pictures. Afterwards these images were combined to create a $3 \mathrm{D}$ volumetric representation of the structure using a reconstruction algorithm. In Computational Tomography a sample is rotated when continuously exposed to $\mathrm{X}$-rays and angular projections are recorded by a detector and stored on a computer. After the acquisition of projec- 
tions over $360^{\circ}$ of rotation, with a step size of $0.5^{\circ}$, they are used in a reconstruction algorithm resulting in a $3 \mathrm{D}$ volumetric description of the "internal" structure.

Mercury intrusion porosimetry (MIP) was performed on small $(30 \times 10 \mathrm{~mm})$ samples to determine the porosity and the pore size distribution in the $\mathrm{Al}$ rear face layer. This technique is based on the principle that mercury is a non-wetting liquid and requires a force to penetrate voids. It is only suitable for the measurement of open and connected pores. The experiments were performed on a $\mathrm{CE}$ instrument Pascal 140 (low pressure) and Pascal 440 (high pressure) in a pressure range from $0.01 \mathrm{kPa}$ to 2 MPa.

Elastic properties of the different solar cell layers were characterized on a polished wafer cross-section by a nano-indentation technique using an MT5 Nanoindenter G200 instrument, capable of continuous stiffness measurements. The tester was equipped with a three-sided pyramid (Berkovich) diamond indenter with a $50 \mathrm{~nm}$ tip radius. The indenter shape was calibrated before testing using a standard indentation procedure. The shape of the indenter was also checked between each series of specimens to track possible tip damage that could lead to inconsistent results. For these experiments, samples were embedded into a cold setting epoxy resin (Epofix) for a better support during indentation. Indentations have been performed at a constant maximum load of $1.5 \mathrm{mN}$. For each specimen, at least 30 different indentations were performed and the mean hardness and Young's modulus values were calculated. If a measurement did significantly differ from the average it was excluded and a new test was performed. The results presented here were obtained after a numerical treatment of the load/depth curves using the Oliver and Pharr method [7].

\subsection{Strength Measurement}

A four-point bending test was chosen in this research because it results in a uniform bending moment across the specimen between the inner loading pins; hence, the specimen will fracture at a point where the largest surface or edge defect is present.

The test configuration, based on the ASTM C 1161$02 \mathrm{c}$, was used to measure the ultimate strength of a beam in bending at ambient temperature $[8,9]$. The four-point bending tests were performed using an Instron 5500R tensile machine with a $100 \mathrm{kN}$ load cell and a testing fixture designed especially for testing thin specimens with a maximum force at fracture of around $10 \mathrm{~N}$. The crosshead speed was set such that the strain rate in the specimen was of the order of 10-4 s-1.

For solar cells specimens the standard formulas are not applicable, because these specimens should be represented as composite beams, consisting of two materials with different stiffnesses, i.e. silicon and the $\mathrm{Al}$ back contact layer [10]. A linear strain distribution is assumed across the composite beam thickness. The stresses are obtained by multiplying the strains by the modulus of elasticity for silicon $\left(E_{\mathrm{Si}}\right)$ and the aluminium metal layer $\left(E_{\mathrm{Al}}\right)$, respectively, leading to the stress distribution shown in Figure 1. The stress distribution is largely affected by the difference in elastic modulus of the silicon wafer and the aluminium layer. In this work the elastic modulus of the silicon was recalculated from the bending tests and on average amounted to $E_{\mathrm{Si}}=170 \mathrm{GPa}$ for different crystalinity types. The elastic modulus of the $\mathrm{Al}$ layer is determined in this work and used for strength calculations.

\section{Results and Discussion}

\subsection{Microstructure of Aluminium Contact layers}

Figure 2(a) shows a SEM micrograph of a polished and etched cross section of a typical screen-printed silicon solar cell consisting of 5 distinct layers: silver, silicon, back surface field (BSF), solid eutectic and porous aluminium. The porous aluminium layer was found to have a complex porous microstructure. A closer look into the porous Al layer (Figure 2(b)) reveals the presence of spherical particles, surrounded by a distinct oxide layer. The thickness of this oxide layer is about $150-200 \mathrm{~nm}$, which is in good agreement with thermo-gravimetrical analysis (TGA). Simultaneous thermal analysis results of three different Al pastes show similar patterns of TGA/ DSC curves (Figure 3). First, a small negative step in the TG curve is found around $180^{\circ} \mathrm{C}$, followed by a larger step around $250^{\circ} \mathrm{C}$, accompanied by an endothermic peak in the DSC curve.

This indicates evaporation of solvent and binders from the $\mathrm{Al}$ paste. After this large step, an exothermal event appears at around $600^{\circ} \mathrm{C}$, together with a small mass increase. This indicates (partial) oxidation of the aluminium in the paste.

This event is immediately followed by an endothermic

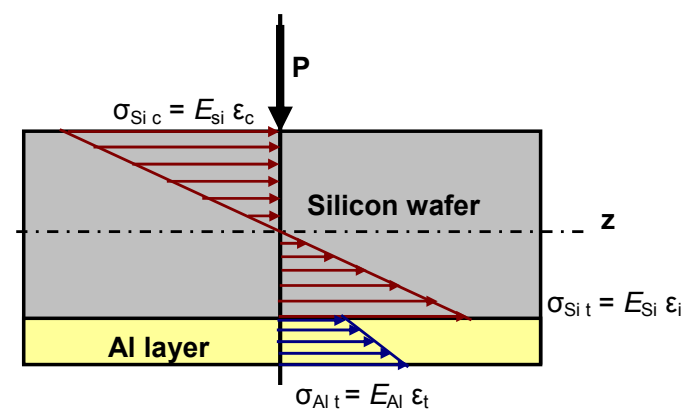

Figure 1. Distribution of stress $(\sigma)$ in a silicon beam with an aluminum layer. 


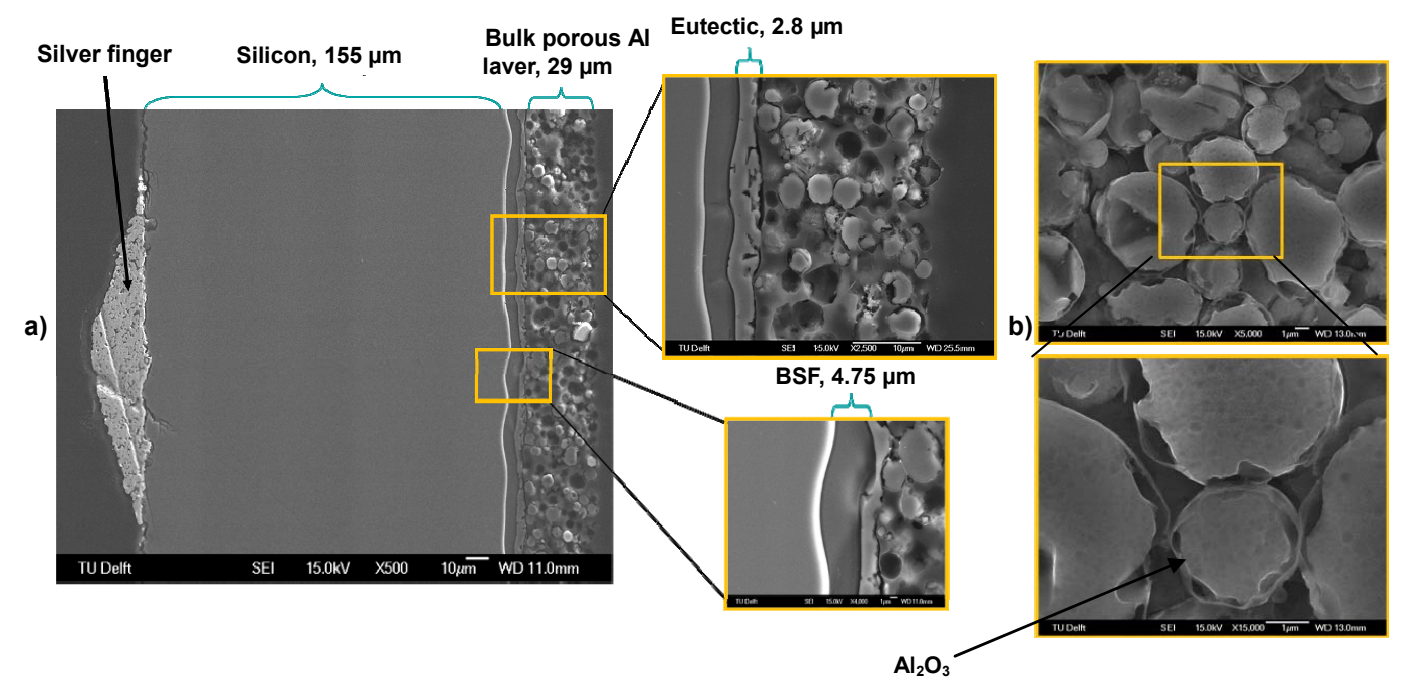

Figure 2. (a) SEM micrograph of a cross section of a conventional silicon solar cell $\left(155 \times 155 \mathrm{~mm}^{2}, 200 \mu \mathrm{m}\right)$, comprising 5 distinct layers; (b) Microstructure of porous Al layer with Al-Si spherical particles, surrounded by a thin film of alumina $\left(\mathrm{Al}_{2} \mathrm{O}_{3}\right)$.

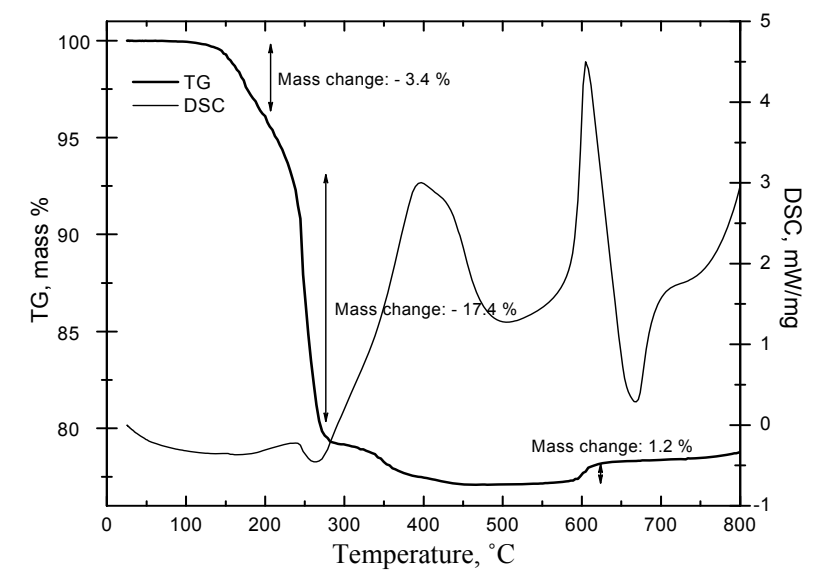

Figure 3. Typical TGA/DSC result for $\mathrm{Al}$ paste during heating.

event with constant mass, around $650^{\circ} \mathrm{C}$, showing the melting of the remaining aluminium.

As can be seen from the EPMA point measurements (Figure 4), the concentration of oxygen increases going from the middle to the edges of the $\mathrm{Al}$ particles. This is consistent with the presence of a thin oxide film, which creates a shell around the particle, which holds the particles in place, and thus creates a stable paste structure. It is expected that particle-to-particle contact is made through the oxide layer. This might lead to only a weak bond between the particles, adversely affecting the mechanical properties of the layer. EDS point analysis is in a good agreement with EPMA results and shows that $\mathrm{Al}$ spherical particles have a nearly eutectic Al-Si composition, surrounded by a complex matrix of $\mathrm{Al}, \mathrm{Si}$ and $\mathrm{O}$ (Figure 5). EDS mapping also shows the presence of $\mathrm{Bi}$

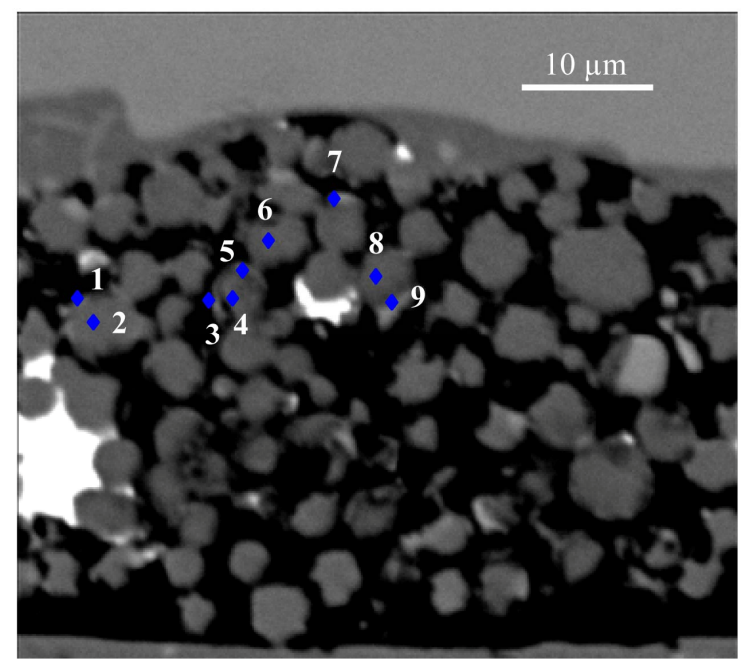

\begin{tabular}{cccc}
\hline Location & $\mathrm{O}$ & $\mathrm{Al}$ & $\mathrm{Si}$ \\
\hline 1 & 11.9 & 70.2 & 17.9 \\
2 & 2.0 & 96.3 & 1.7 \\
3 & 27.8 & 54.4 & 18.0 \\
4 & 9.7 & 88.4 & 1.9 \\
5 & 13.0 & 43.5 & 43.4 \\
6 & 2.4 & 96.0 & 1.6 \\
7 & 7.8 & 47.3 & 44.9 \\
8 & 3.6 & 94.8 & 1.6 \\
9 & 7.8 & 6.6 & 85.6 \\
\hline
\end{tabular}

Figure 4. Locations of the individual EPMA measurements and corresponding compositions (wt\%). 


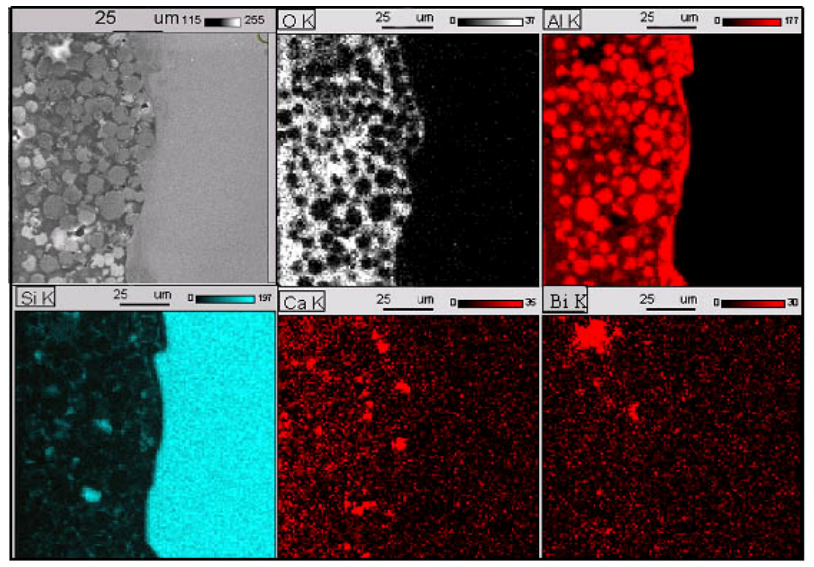

Figure 5. EDS mapping of a cross section of the Al-Si layer, indicating the distribution of selected elements.

and $\mathrm{Ca}$, which is a residue from the initial $\mathrm{Al}$ paste. The particle size distribution analysis showed that $\mathrm{Al}$ particles size increases up to $40 \%$ in its diameter after firing at $850^{\circ} \mathrm{C}$ (Figure 6). This might indicate on a diffusion of $\mathrm{Si}$ phase inside $\mathrm{Al}$ particles, explaining the presence $\mathrm{Si}$ lamellas in the as-fired $\mathrm{Al}$ paste.

An XRD analysis was performed on the back surface of the cell in order to identify phases present in the Al layer. Measurements were performed for both a mechanically removed Al layer and an as-processed layer on top of a $\mathrm{Si}$ wafer. Figure $\mathbf{7}$ shows the X-ray spectrum of the $\mathrm{Al}$ paste, mechanically removed after firing. Besides the expected $\mathrm{Al}$ and $\mathrm{Si}$, three extra phases were detected, namely $\gamma-\mathrm{Al}_{2} \mathrm{O}_{3}, \mathrm{CaMgSiO}_{4}$, and bismuth silicon oxide.
The latter two are a residue of the initial glass frit present in the $\mathrm{Al}$ paste to obtain better sintering properties of the contact layer. The presence of $\gamma-\mathrm{Al}_{2} \mathrm{O}_{3}$ is in good agreement with literature results, showing a formation of amorphous alumina between $300^{\circ} \mathrm{C}$ to $550^{\circ} \mathrm{C}$ and its further transformation into $\gamma-\mathrm{Al}_{2} \mathrm{O}_{3}$ at about $550^{\circ} \mathrm{C}$ [11].

In order to evaluate the ratio between $\mathrm{Al}$ and $\mathrm{Si}$ in the Al back surface layer a full profile Rietveld refinement was performed, employing FullProf software. As a starting model for the refinement, bulk $\mathrm{Al}$ and $\mathrm{Si}$ structures were used; glass phases were not included in the refinement. The refinement provided good agreement between observed and calculated profiles. The estimated weight ratio between $\mathrm{Al}$ and $\mathrm{Si}$, e.g. 83:17, is in good agreement with EDS/EPMA results.

A computed tomography analysis was carried out to obtain the amount and distribution of bismuth silicate glass and porosity. Figure 8(a) shows a representative 2D X-ray image of the Al layer (paste B). The yellow parts correspond to a higher atomic number material (bismuth, $\mathrm{Z}=83$ ), which absorbs more $\mathrm{X}$-rays, and grey parts to lower atomic number materials, such as aluminium $(Z=13)$ and silicon $(Z=14)$. Based on the digital 3D images of Figure 8(b), the fraction of bismuth glass and of porosity in paste B was estimated to be 3.9 and 14 vol\%, respectively. Results for the other pastes are presented in Table 1.

The overall open porosity of the Al layer, estimated by mercury intrusion porosimetry, was found to be around $15 \%$, which is in good agreement with computed tomo-

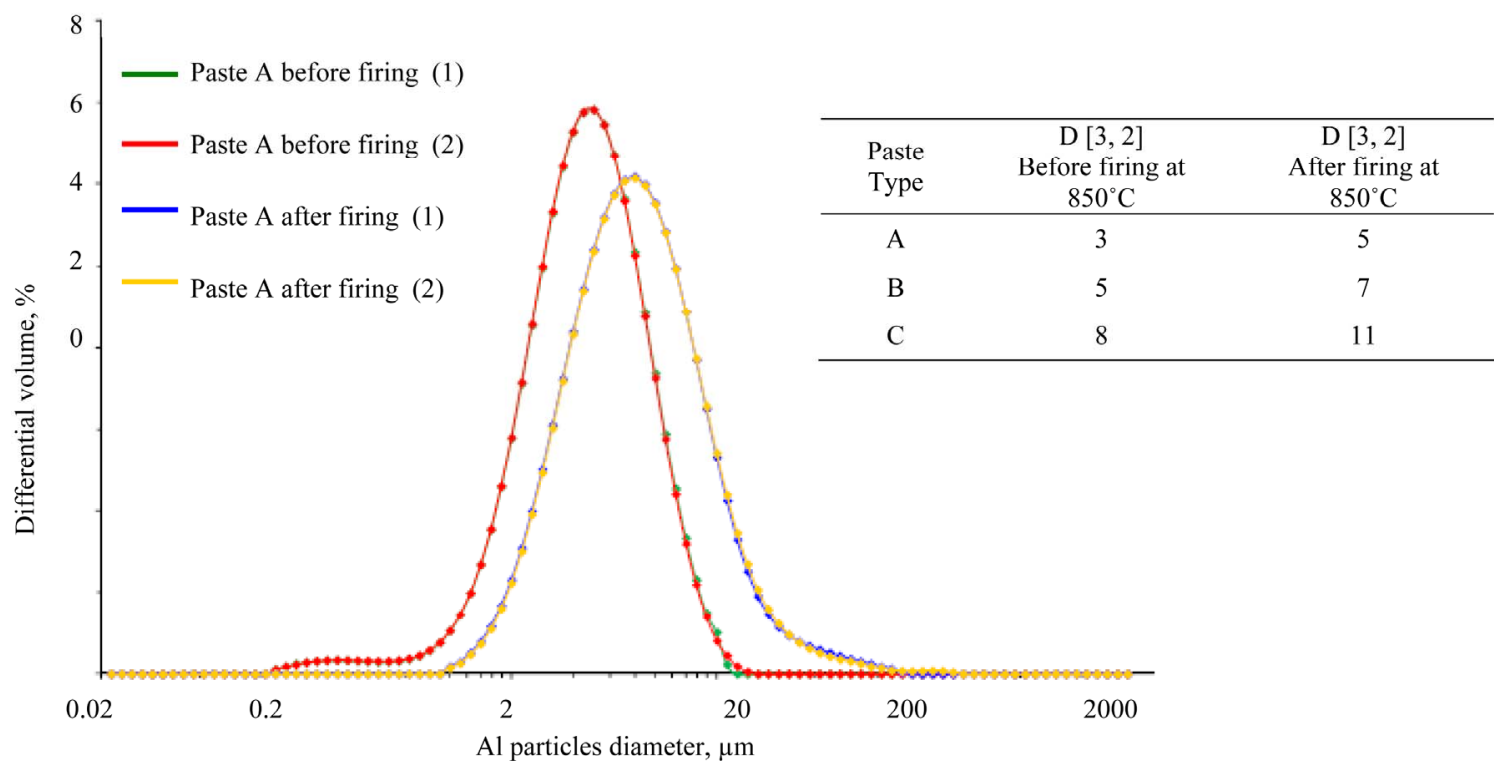

Figure 6. Particle size distribution data of the aluminium paste samples before and after firing treatment and a representative curve of aluminium paste $A$ before and after firing showing the difference in particles size diameter. (Where, D[3, 2]: Surface weighted mean diameter $\left.\left(\Sigma \mathbf{n}_{\mathbf{i}} \mathbf{D}_{\mathbf{i}}^{3}\right) /\left(\Sigma \mathbf{n}_{\mathbf{i}} \mathbf{D}_{\mathbf{i}}^{2}\right)\right)$. 


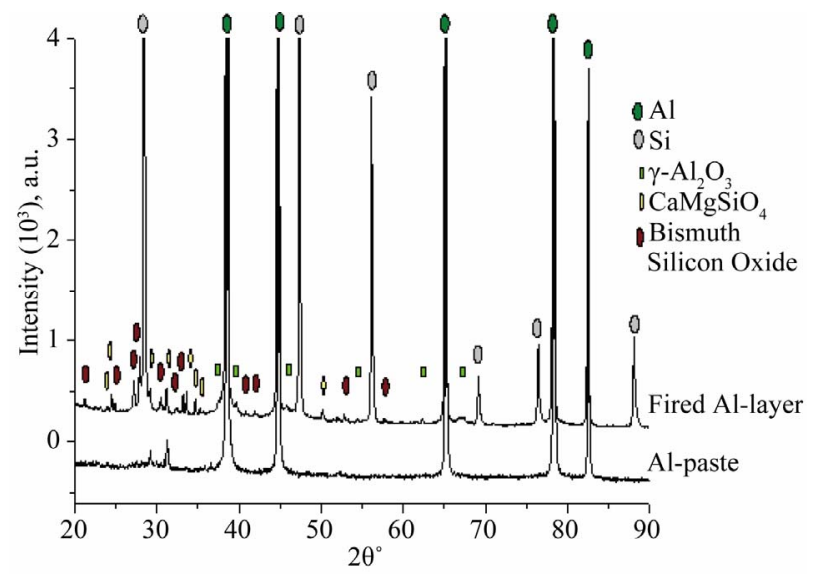

Figure 7. XRD spectrum of the initial dried Al paste and mechanically removed $\mathrm{Al}$ paste after firing on top of silicon wafer.

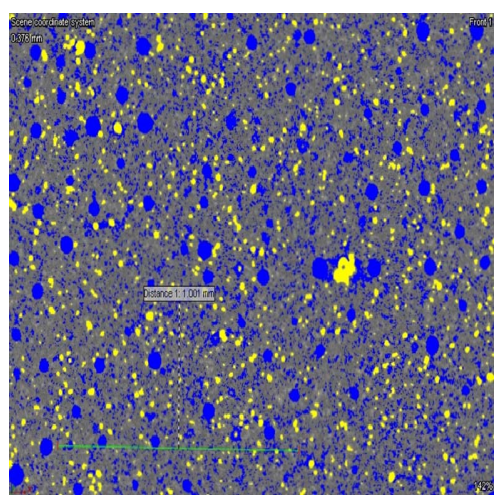

(a)
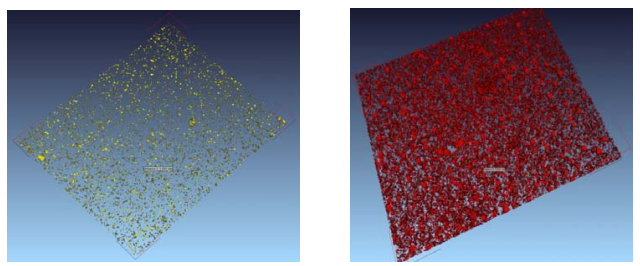

(b)

Figure 8. (a) 2D X-ray image of the Al layer (paste B), showing the differences in photographic density between different parts (yellow part: bismuth, blue: porosity, grey: $\mathrm{Al}$ and $\mathrm{Si}$ ); (b) 3D volumetric representation of bismuth glass phase (upper) and porosity (lower) distributions.

graphy results. Mercury intrusion showed that at a relatively low pressure $(0.06 \mathrm{MPa})$ filling of large pores (around 50 microns) occurs. An increase in pressure (0.5 - $2 \mathrm{MPa}$ ) revealed the filling of the remaining small pores, which are about 2 microns in size.

\subsection{Elastic Properties of the Porous Bulk Aluminium Layer}

Elastic properties of Al particles inside the porous alu- minium layer were experimentally obtained by doing nano-indentation, on a MTS NanoIndenter-XP equipped with a three-sided pyramid (Berkovich) diamond indenter, performed in a load controlled mode. It was empirically verified that a straightforward way of determining whether the nano-indentation (force-displacement $[\mathrm{P}, \mathrm{h}])$ curves obtained on a material were acceptable was to compare curves corresponding to a set of identical experimental conditions. During the experiment, it was noticed that the force-displacement $[\mathrm{P}, \mathrm{h}]$ curves are significantly affected by the mechanical stability of the sample. A lack of stability leads to an apparent increase of penetration depth and an underestimate of the Young's modulus. A simple metallic clamping of the specimen in the holder was unsatisfactory in most cases. The best solution found to avoid micro-displacements of the sample during indentation was to place it in an epoxy resin (Epofix) holder. This also made it possible to obtain a smoother surface during polishing, which improved measurement accuracy. With such a procedure, it was observed that the tendency of sample micro-motions was greatly reduced and more reproducible curves could be obtained.

Nevertheless, the first results showed a large spread and a tendency for cracking of $\mathrm{Al}$ particles and interfaces between the particles was noted. Optical observations of the surfaces revealed significant roughness and the presence of a large number of defects taking the form of $\mathrm{Al}$ particle pull-outs and micro-scratches originating from polishing. When indenting those samples, the indenter first makes contact with micro-asperities which are then deformed in an elasto-plastic manner. As the load rises, micro-cracks tend to develop in the sub-surface of the material, which can lead to material crushing in severe cases $[12,13]$. These forms of damage are responsible for a significant enhancement of the material compliance, resulting in a decrease of the Young's modulus, as observed in this work.

It must be pointed out that even after optimizing the polishing and clamping procedure of solar cell crosssections, a significant amount of surface defects was still noticeable. In such circumstances, it is important to use the combination of experimentally obtained data, such as force-displacement $[\mathrm{P}, \mathrm{h}]$ curves, and a direct observation afterwards of each indented particle in order to interpret the results. This reduces possible side effects of surface micro-asperities, pre-existing micro-cracking and sample motion in nano-indentation.

Figure 9 shows a schematic illustration of indentation force-displacement data as well SEM micrographs of the indented Al layer cross section.

Young's modulus of the Al-Si particles in the porous bulk $\mathrm{Al}$ layer was found to be approximately $44.5 \mathrm{GPa}$ at 
Table 1. Correlation between aluminium paste composition, bowing and Young's modulus of the fired aluminium rear side contact.

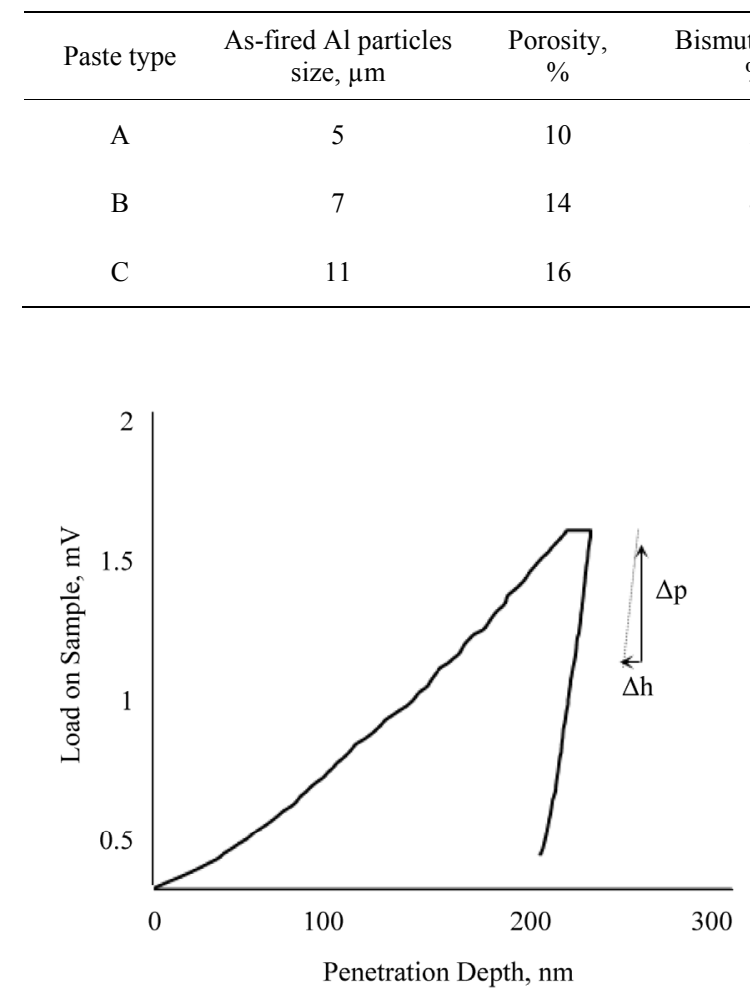

(a)

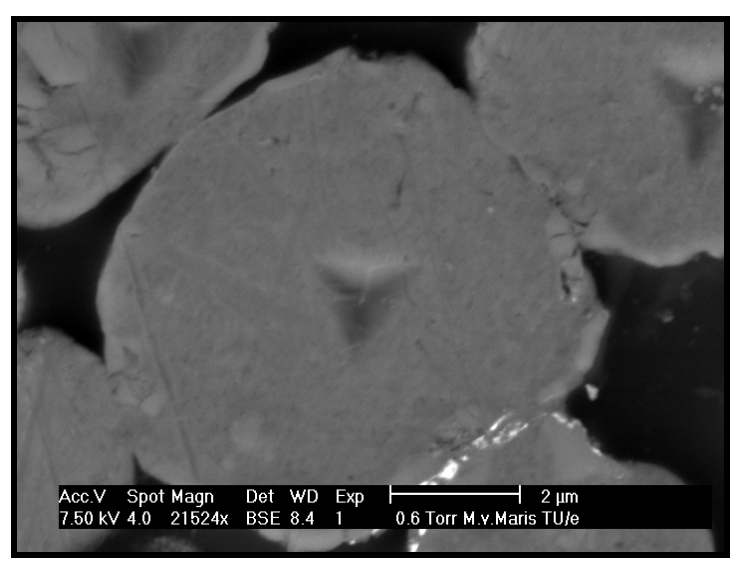

(c)

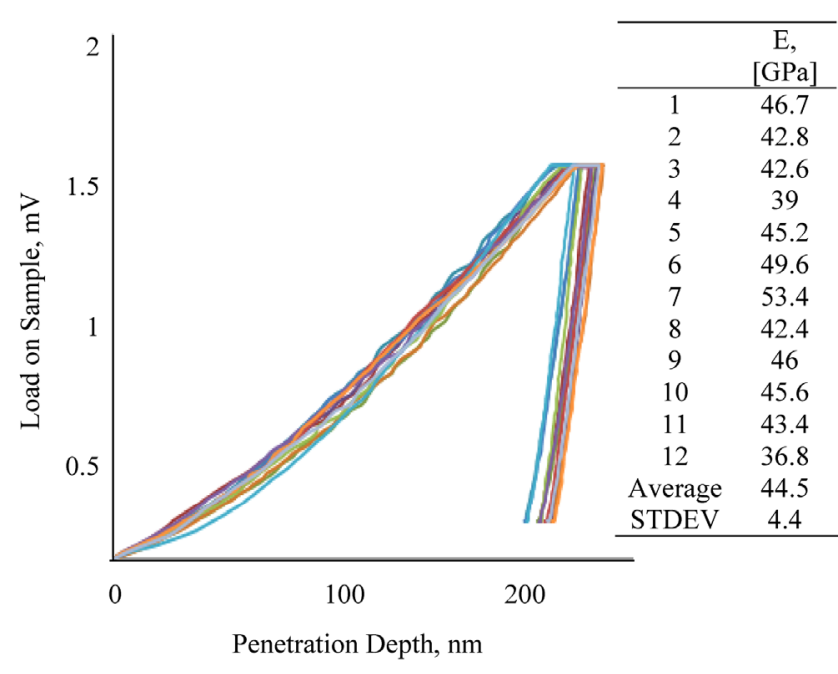

(b)

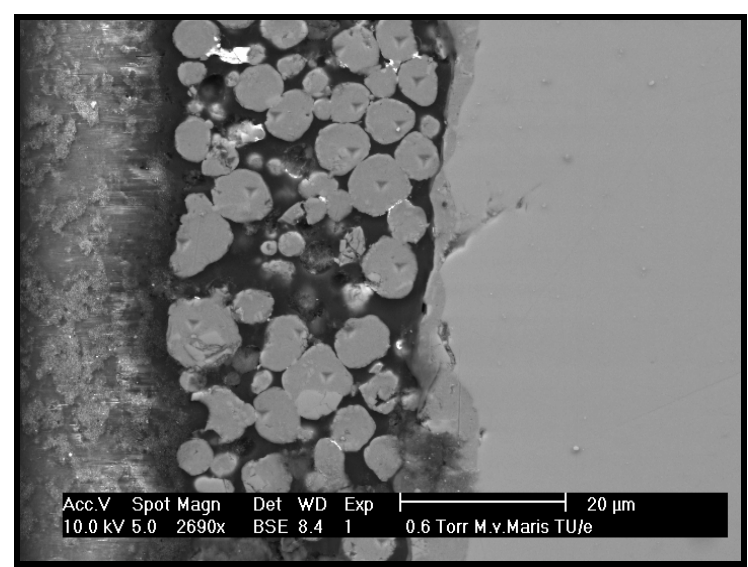

(d)

Figure 9. (a) Schematic illustration of indentation force-displacement data, were the elastic unloading stiffness, $\mathrm{S}=\Delta \mathrm{P} / \Delta \mathrm{h}$, defined as the slope of the upper portion of the unloading curve during the initial stages of unloading (contact stiffness) [7] and (b) the representative force-displacement $[\mathrm{P}, \mathrm{h}]$ curves of the indented $\mathrm{Al}$-Si particles in the porous Al-layer surface cross section which are shown in the SEM micrographs; (c) Single particle and (d) the complete indented surface.

$1.5 \mathrm{mN}$. However, this value is not representative for the elastic modulus of the porous composite like Al layer as a whole. In order to confirm this value, theoretical calculation was performed based on the experimentally measured bowing of the as-fired Al layer attached to silicon solar wafer.
Bowing of material layers in contact with each other having different thermal expansion coefficients ( $\mathrm{Si}$ and Al in this case) can be represented by a bimetallic strip model. Assuming bowing in one dimension and only elastic deformation, the resulting deflection, $\delta$, over a length L can be calculated using [3]: 


$$
\delta=\frac{3\left(\alpha_{\mathrm{Al}}-\alpha_{\mathrm{Si}}\right)\left(T_{f}-T_{m}\right)\left(t_{\mathrm{Al}}+t_{\mathrm{Si}}\right) L^{2}}{4 t_{\mathrm{Al}}^{2}\left(4+6 \frac{t_{\mathrm{Si}}}{t_{\mathrm{Al}}}+4\left(\frac{t_{\mathrm{Si}}}{t_{\mathrm{Al}}}\right)^{2}+\left(\frac{E_{\mathrm{Si}}}{E_{\mathrm{Al}}}\right)\left(\frac{t_{\mathrm{Si}}}{t_{\mathrm{Al}}}\right)^{3}+\left(\frac{E_{\mathrm{Al}}}{E_{\mathrm{Si}}}\right)\left(\frac{t_{\mathrm{Al}}}{t_{\mathrm{Si}}}\right)\right)}
$$

where $t$ is the layer thickness, $\alpha$ is the coefficient of thermal expansion, $T_{\mathrm{f}}$ is the firing temperature (contact formation temperature), $T_{\mathrm{m}}$ is the measuring temperature (room temperature) and $E$ is the Young's modulus.

Using experimentally obtained bowing results and Equation (1), the Young's modulus of the Al contact layer can be calculated. It should be noted that, since this bimetallic strip model accounts only for two layers, the value obtained for the Young's modulus should be considered as an average for the combination of the porous part of the Al layer and the solid eutectic layer. Table 1, shows the compositions of the three pastes, the amount of bowing and the calculated average Young's moduli for the respective aluminium layers. As can be seen theoretical Young's modulus is in good agreement with experimental Young modulus obtain by Nanoindentation. Furthermore, there seems to be a correlation between the aluminium paste composition (porosity and bismuth glass concentration), bowing and Young's modulus. A more detailed investigation on the relation between these parameters is outside the scope of this paper and will be presented in a follow-up article.

Based on the results obtained in this paper, a model was made describing the cross section of the rear face of the silicon solar cell with corresponding microstructural features (Figure 10). The Al layer is represented as a complex composite-like material, consisting of three main components: 1) spherical (3 - $5 \mu \mathrm{m})$ hypereutectic Al-Si particles, surrounded by a thin aluminium oxide layer $(200 \mathrm{~nm}) ; 2)$ a bismuth-silicate glass matrix (3.3 $\mathrm{vol} \%$, as an average of three different $\mathrm{Al}$ pastes); 3 ) pores (14 vol\%).

The results of microstructure, nano-indentation analyses and bowing measurements are used in a thermomechanical multi-scale model of a solar cell. The model integrates the thermo-mechanical behaviour of the layers at the rear of the cell, allowing bowing of the whole cell to be predicted [14].

\subsection{Effect of Al Paste Type on Mechanical Strength of Silicon Solar Cells}

Three types of aluminium metal pastes were investigated in order to find the effect of composition on the mechanical strength of silicon solar cells. It was found that there is a large variations in eutectic layer thickness, namely the thickness of the alloy is largest at the valley of the texture and a minimum at the peak of the texture.
This indicates that during the formation of Si-Al alloy, the melt initially fills up the texture valley. However, this effect is less pronounced for the Paste A with small Al particle size (1 - 3 microns) and the waviness seem to increase with increasing the Al particle size. It was concluded that the eutectic layer waviness depends on $\mathrm{Al}$ particle size, amount of Al paste and textured surface roughness of silicon wafers. These microstructural features should be taken in account when discussing the strength of solar cells.

It should be noted, that specimens were treated as composite beams, consisting of two layers, namely: bulk mc-silicon wafer and an aluminium layer. Thus, the bending strength of the specimens was corrected using the appropriate flexural formulas [8]. Using these formulas, it was possible to determine the maximum stress in each layer at the moment of specimen fracture.

As can be seen from Table 2, aluminium metallization paste types have a significant effect on the strength when the specimens are loaded with the Al layer in tension. In this loading position, both of the specimen layers, i.e. the silicon wafer and the Al layer, are loaded in tension. Furthermore, the silicon wafer experiences the highest tensile stresses.

On the other hand, for a reversed loading position the effect on the mechanical strength is not so significant.

It should be noted that specimens with an Al layer show an increase in bending strength (as compared to the reference silicon wafer specimens), possibly due to the formation of a eutectic layer $(\sim 12 \% \mathrm{Si})$ and a BSF layer $\left(1-2 \times 10^{18}\right.$ atom $\left.\mathrm{Al} / \mathrm{cm}^{3} \mathrm{Si}\right)$. The maximum tensile stress in the silicon wafer will be located at the interface between the silicon wafer surface and aluminium bulk layer, i.e. in the eutectic and the BSF layer. In order to understand why, it is important to take into account the microstructure of each layer.

The eutectic layer as well as its interface with the porous layer will have a significant effect on changing the mechanical behavior of the silicon wafer at the outer fiber. Since silicon is a very brittle material that exhibits linear elastic behavior, the presence of a 2nd ductile phase (i.e. the eutectic layer) could induce some plasticity at the outer fiber; thus, altering the stress distribution and affecting possible crack initiation. Furthermore, this ductile phase (eutectic layer) can serve as a bridge for possible critical cracks, thus improving the strength of mc-silicon solar cells. 


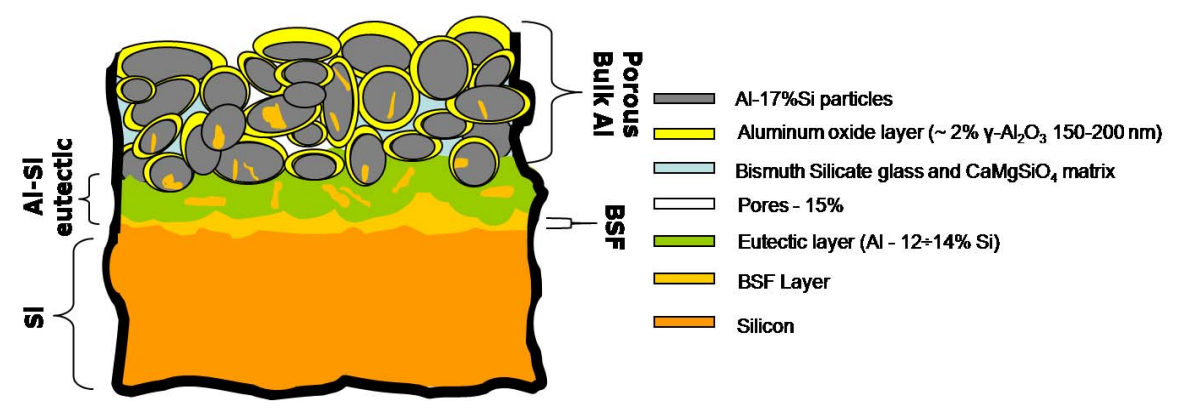

Figure 10. Model of the rear face of a silicon solar cell with corresponding microstructural features.

Table 2. Bending test results and microstructure properties of aluminium paste.

\begin{tabular}{cccccc}
\hline \multirow{2}{*}{ Paste } & \multicolumn{2}{c}{ Characteristic stresses at fracture $(\mathrm{MPa})$} & $\begin{array}{c}\text { Porous Al layer/ } \\
\text { Eutectic layer thickness, } \mu \mathrm{m}\end{array}$ & $\begin{array}{c}\text { Porosity (vol\%) } \\
\text { Bismuth glass fraction } \\
(\mathrm{vol} \%)\end{array}$ \\
\cline { 2 - 5 } & $\sigma_{\mathrm{Si}}\left(\mathrm{Al}_{\text {tension }}\right)$ & $\sigma_{\mathrm{Al}}\left(\mathrm{Al}_{\text {tension }}\right)$ & $34 / 5.3$ & 10 & 2 \\
$\mathrm{~A}$ & 235 & 100 & $36 / 6$ & 14 & 4 \\
$\mathrm{~B}$ & 204 & 71 & $46 / 7.3$ & 16 & 5 \\
\hline
\end{tabular}

The different effects of $\mathrm{Al}$ pastes on the mechanical strength of mc-silicon solar cells can be explained by the differences in microstructures. There are a number of microstructural features that might affect the mechanical strength, such as Al layer thickness, porosity, bismuth glass fraction and the thickness of the eutectic layer.

In general, three main parameters affect the mechanical strength of mc-silicon solar cells with an aluminium contact layer, namely the eutectic layer thickness and uniformity, the $\mathrm{Al}$ layer thickness (which results from the Al particle size and its distribution), and the amount of porosity and the bismuth glass fraction.

\section{Conclusion}

In this work the microstructure and mechanical properties of the fired aluminium layer on the rear face of a solar cell and its effect on the mechanical strength were investigated. It is shown that the outer porous part of the Al layer has a complex composite-like microstructure, consisting of three main components: 1) spherical (3 - 5 $\mu \mathrm{m})$ hypereutectic Al-Si particles, surrounded by a thin aluminium oxide layer (150 - $200 \mathrm{~nm}) ; 2$ ) a bismuthsilicate glass matrix $(3.3 \%)$ and 3$)$ pores $(14 \%)$. The Young's modulus of the $\mathrm{Al}$ porous layer, obtained by nano-indentation, was found to be $44.5 \mathrm{GPa}$ and showed a good agreement with theoretically calculated Young's modulus, based on bimetallic strip model. There is a relation between aluminium paste composition, mechanical strength and bowing. In case of the aluminium layer, the eutectic layer can induce some plasticity at the outer fiber of the silicon wafer and can serve as a bridge for possible critical microcracks at the silicon wafer surface, thus improving the strength of the mc-silicon wafer. Three main parameters affect the mechanical strength of mcsilicon solar cells with an aluminium contact layer, namely the eutectic layer thickness and uniformity, the $\mathrm{Al}$ layer thickness (which results from the Al particle size and its distribution), and the amount of porosity and the bismuth glass fraction. These results are used as input parameters for an improved thermo-mechanical multiscale model of a silicon solar cell, which incorporates the behaviour of the various layers.

\section{REFERENCES}

[1] T. van Amstel, V. A. Popovich, P. C. de Jong and I. G. Romijn, "Modeling Mechanical Aspects of the Aspire Cell," Proceedings of the 23rd European Photovoltaic Solar Energy Conference, Valencia, 2008.

[2] F. Huster, "Investigation of the Alloying Process of Screen Printing Aluminum Pastes for the BSF Formation on Silicon Solar Cells," 20th European Photovoltaic Solar Energy Conference, Barcelona, 2005.

[3] F. Huster, "Aluminum-Back Surface Field: Bow Investigation and Elimination," 20th European Photovoltaic Solar Energy Conference and Exhibition, Barcelona, 2005, pp. 635-638.

[4] S. Kim, "Aluminum Paste (Lead-Free/Low Bow) for Thin Wafers," IEEE 31st Photovoltaic Specialists Conference and Exhibition, Orlando, 2004.

[5] J. T. Armstrong, "Quantitative Elemental Analysis of Individual Microparticles with Electron Beam Instruments," In: K. F. J. Heinrich and D. E. Newbury, Eds., Electron Probe Quantitation, Plenum Press, New York, 1991, pp. 261-315.

[6] http://icsdweb.fiz-karlsruhe.de/index.php 
[7] W. C. Oliver and G. M. Pharr, "An Improved Technique for Determining Hardness and Elastic Modulus Using Load and Displacement Sensing Indentation Experiments," Journal of Materials Research, Vol. 7, No. 6, 1992, pp. 1564-1583. doi:10.1557/JMR.1992.1564

[8] ASTM C1161-02c, Standard Test Method for Flexural Strength of Advance Ceramics at Ambient Temperature, 2008.

[9] ASTM C1341-06, Standard Test Method for Flexural Properties of Continuous Fiber-Reinforces Advance Ceramic Composites, Current Edition, 2006.

[10] J. M. Gere and B. J. Goodno, "Mechanics of Materials," Seventh Edition, Cengange Learning, 2009.

[11] M. Trunov, et al., "Effect of Polymorphic Phase Transformations in $\mathrm{Al}_{2} \mathrm{O}_{3}$ Film on Oxidation Kinetics of Alu- minum Powders," Combustion and Flame, Vol. 140, No. 4, 2006, pp. 310-318. doi:10.1016/j.combustflame.2004.10.010

[12] Z. Peng, J. Gong and H. Miao, "On the Description of Indentation Size Effect in Hardness Testing for Ceramics: Analysis of the Nano-Indentation Data," Journal of the European Ceramic Society, Vol. 24, No. 8, 2004, pp. 2193-2201. doi:10.1016/S0955-2219(03)00641-1

[13] M. Warmuzek, "Aluminum-Silicon Casting Alloys: Atlas of Micrographs," ASM International, 2004.

[14] T. van Amstel, V. A. Popovich, P. C. de Jong and I. J. Bennett, "A Multiscale Model of the Aluminium Layer at the Rear Side of a Solar Cell," Proceedings of the 24th European Photovoltaic Solar Energy Conference, Hamburg, 2009. 